\title{
EPISTEMIC DIALOG BETWEEN HEALTH SERVICES AND OPERATIONS RESEARCH
}

\author{
Maria Stella de Castro Lobo* \\ Epidemiology and Evaluation Department (SEAV) \\ University Hospital Clementino Fraga Filho (HUCFF) \\ Federal University of Rio de Janeiro (UFRJ) \\ Rio de Janeiro - RJ, Brazil \\ ms.lobo@superig.com.br \\ Marcos Pereira Estellita Lins \\ Operations Research / Production Engineering \\ Federal University of Rio de Janeiro (UFRJ) \\ Rio de Janeiro - RJ, Brazil \\ estellita@pep.ufrj.br \\ * Corresponding author / autor para quem as correspondências devem ser encaminhadas \\ Recebido em 03/2009; aceito em 03/2010 após 2 revisões \\ Received March 2009; accepted March 2010 after two revisions
}

\begin{abstract}
The study proposes a dialogical approach between OR and Health Services Planning and Epidemiology based on the similarities of their own epistemological experiences, according to Habermas' Theory of Knowledge. As a field of application, healthcare services planning and epidemiology are characterized as Complex Societal Problems, requiring multidisciplinary and multi dimensional approaches. A review of the literature on OR efficiency healthcare services applications is made to confront the perspective of the OR analyst and that of the health manager. Finally, an agenda is proposed to enhance the interaction between the disciplines, by increasing actuality of the OR methods' findings, to guarantee that the results of health services research will really be put in practice by health policy decision makers.
\end{abstract}

Keywords: epistemology; soft OR; data envelopment analysis; complex societal problems; health planning; health services epidemiology.

\section{Resumo}

O estudo propõe uma aproximação dialógica entre a Pesquisa Operacional (PO) e o Planejamento e Epidemiologia de Serviços de Saúde, a partir das semelhanças epistemológicas vivenciadas por cada uma destas disciplinas, e de acordo com a teoria do Conhecimento de Habermas. Como campos de aplicação, o planejamento e a epidemiologia de serviços de saúde podem ser considerados como problemas sociais complexos e, portanto, requerem abordagens multidisciplinares e multidimensionais. De modo a se confrontar as perspectivas distintas dos analistas de PO e dos gestores da saúde, realiza-se uma revisão da literatura sobre estudos de desempenho e eficiência de serviços de saúde. Finalmente, é proposta uma agenda que induza uma interação mais sistemática entre estas disciplinas, por meio da divulgação das inovações metodológicas advindas da PO, para que os resultados das pesquisas sobre serviços de saúde possam de fato ser postos em prática pelos tomadores de decisão no âmbito das políticas públicas de saúde.

Palavras-chave: epistemologia; PO soft; análise envoltória de dados; problemas sociais complexos; planejamento em saúde; epidemiologia de serviços de saúde. 


\section{Introduction}

There is much criticism concerning approaches to OR health care that look for databases aiming to feed a mathematical model and disregarding significant societal contexts. Besides, the easiness for development and spread of simulation and optimization softwares have generated many scientific publications that, when presenting results detached from reality, contribute to weaken the reliability of these important and useful tools to solve complex societal problems, as is the case of health services planning and evaluation (Hollingsworth, 2003).

The present study tries to unfold this problem and propose a dialogical approach between the two different disciplines involved in this correspondence: OR and health services research epidemiology, to enhance its usefulness and validity. That is, if we intend to apply the operations research scientific discipline to solve problems related to the field of health services planning policy, we need to discuss the state of art of their own postulates, conclusions, cognitive validity, structural paradigms and the relationship with society and history. This epistemological first step is an appropriate way to guarantee the acceptance of the results by the scientific community related to the field of application (health professionals and managers, in this case). In summary, before any application, we need to know if the scientific disciplines are speaking the same language; and also to look for ways of convergence of their priorities and different points of view, while searching for complementary bonds.

In the second section, we present a summary of the epistemological developments following Ackoff's seminal questioning on the social role of the OR discipline, its deviance from the "real world" priorities and its limitation for solving dynamic and complex societal problems (Ackoff, 1979a).

The third section will present the state of art of epidemiology and health planning, especially with respect to their role for implementing health policy in Latin America.

The correspondence between OR, epidemiology and health planning and the similarities of their own epistemological approaches will be summarized in the fourth section.

The fifth section will characterize health as a complex societal problem and present a brief literature review on OR health services' efficiency publications, considering both perspectives: the one from the OR analyst and the other from the health professional or manager.

We believe that, after this encounter and synthesis, an agenda for a multidisciplinary health services research can be constructed and legitimated, as will be presented in the conclusive sixth section.

\section{General Foundations for Operations Research Health Applications: the future of OR is NOT past}

According to Rosenhead's definition (2001), OR is a "process of offering aid to organizational decision making through the construction of a model representing the interaction of relevant factors, which can be used to clarify the implications of choice". As pointed by Gass \& Assad (2005): "As implied by its dictionary definition, OR's distinguishing characteristic is that OR applies its scientific and technological base to resolving problems in which the human element is an active participant. As such, OR is the 
science of decision making, the science of choice". This emphasis opens fundamental questions regarding not only a multidisciplinary, but a multiple perspectives/multiple agents approach.

The discipline was first developed in the 30's as an essentially applied science, initially used to aid military decision making, based mainly on simulation and linear programming techniques, and thereafter was highly adopted by administrative circles and corporations (until the 60's, along with the academic and managerial dissemination of the discipline, it was called the "golden age" of OR; Kirby, 2007). In the 70's, an internal criticism appeared inside the OR community, as published by Hall \& Hess (1978, "OR/MS Dead or Dying? RX for Survival" apud Ackoff, 1999), who suggested to reinforce the bond between academic and non-academic practitioners, and by Tosher (1977, apud Ackoff, 1999), who proposed a more profound disciplinary change by questioning the suitability for the paradigm of OR at that moment to solve societal problems. Rosenhead had this same point of view when dealing with the area of health services planning (1978, apud Ackoff, 1999).

In this scenario, Ackoff (1979a), wrote an anthological paper: "The Future of Operational Research is Past", where he assumed that the academic practice of OR has abstracted from the real world and "came to be identified with the use of mathematical models and algorithms rather than the ability to formulate management problems, solve them, and implement and maintain their solutions in turbulent (messy) environments". In this way, OR could no more aid strategic decisions of the organizations, losing its multidisciplinary skill to deal with complex problems.

Concerning the problems' approach, and according to the systems thinking theory, Ackoff also considered that OR just looked after the organizations' reasons (assuming a self-control attitude, using optimization methods and objectivity values), but usually didn't pay attention to its purposeful parts (lack of humanization) and/or to the larger and dynamic environmental context. In an attempt to get through these shortcomings as an applied science, a second paper was written: "Resurrecting the Future of Operational Research" (1979b), where Ackoff proposes to:

a) Develop decision-making systems that could learn and adapt to an ever changing environment;

b) Use of aesthetic values - stylistic preferences and ideals - that are relevant to quality of life;

c) Look for holistic treatment to the systems of messes inside larger messes;

d) Promote a paradigmatic change, from a preventive "predict and prepare" attitude to a creative "design a desirable future and create ways to reach it";

e) Reassume multidisciplinary approach;

f) Always incorporate the multitude of perspectives of all persons/ actors/ stakeholders affected by the problem.

30 years later, Kirby (2007) shows how this debate is still strongly present in the OR community. After generating a "crisis of confidence" in the discipline, it promoted the development of new insights and methodologies, mainly inside the European continent. Cited as a "Kuhnian" crisis at the 70's, according to Dando \& Bennett (1981, apud Kirby, 2007), because the dominant framework of assumptions appeared to fail in relation to important problems, three different paradigms could be derived from it: 
a) The classical, positivist/quantitative, mechanicist, hard one, rooted on objective mathematical models or the "established methods of science", which is a worldwide prevailing reference for OR community;

b) The reformist or participative paradigm, advocated by Ackoff (USA) and Checkland (United Kingdom), focused on an interactive planning and a social commitment, which borrowed the methodology from the social sciences and proposed the use of techniques of soft OR, placing particular emphasis on the insertion of subjectivity inside the modelling process, comprehension and structuring of the complex social problems and action-research;

c) The revolutionary, critique or emancipatory paradigm, presented by Rosenhead \& Thunhurst (1982, apud Kirby, 2007), which sought to guarantee that the technological and societal development OR results would be useful for all society, and not only for the dominant classes. This was the embryo of the community OR.

The awareness brought about by OR systematic thinking and modelling of a problem, focusing on the big picture; evolved into several trends for integrating social, environmental and political issues, through Structuring Methods (Rosenhead, 1989). Systems thinkers developed approaches such as system dynamics (DeTombe \& Hart, 1996), soft systems methodology (SSM) (Checkland \& Scholes, 1990) interactive planning (Ackoff, 1981) and critical systems heuristics (Ulrich, 1994) to deal with conflicts in complex societal problems.

Cynthia Barnhart, in charge of INFORMS presidency, aimed at "engaging OR students in using OR to address important societal problems and provide important insights that can be used to inform and shape public policy". She launched the "Doing Good with Good OR" initiative, focusing on three daunting and immediate societal challenges: energy and environment, public health and air congestion, showcased at the 2008 INFORMS Annual Meeting in Washington D.C.

Vidal (2006) discusses these paradigmatic categories, in line with Habermas theory of knowledge (Habermas, 1992). According to the German philosopher, man possesses three generic cognitive modes in which human interest generates knowledge: Technical, Practical and Emancipatory.

Technical knowledge refers to how human beings control and manipulate world resources, assuming that there is an objective reality and that empirical-analytic sciences - like Physics, Chemistry and Biology - can make use of hypothetical-deductive theories to predict and control natural and social systems. This was the paradigm accepted by the classical OR approach.

The Practical knowledge paradigm is informed by the "communicative rationality" or "communicative action", based on human social interaction achieved by the participative encounter and consensus of shared subjectiveness. In contrast to the first paradigm, intersubjectivity requires the understanding of meaning rather than causality, of the mutual understanding of intentions, motives and values, bounded by formal rules and guided by consensual norms. The idea of a dialogical understanding requires a more rational justification on the isolated judging subject than would a monological one. Practical knowledge is characterized, according to Habermas, by hermeneutic disciplines like, anthropology, sociology, social science, history, and legal.

Considering that both paradigms, positivist and reformist, can suffer distortions by the sociopolitical environment and power structures of society, the critical paradigm appears as a 
necessity. Moreover, the Emancipatory, critical or revolutionary paradigm focus human interest on "self-knowledge" or "self-reflection" in order to emancipate from institutional, cultural and power relationships which limit our options and rational control over our lives but have been taken for granted as beyond human control. Knowledge gained through critical self-awareness are emancipatory in the sense that at least one can recognize the correct reasons for his or her problems, leading to a transformed consciousness or 'perspective transformation'. Examples of critical sciences include feminist theory, psychoanalysis and the critique of ideology, according to Habermas.

Nowadays, the three paradigms coexist, confronting themselves in a reflexive mode of conversation (Morgan, 1986).

Additionally, a second line of thought took place around the ethical approaches to each variant paradigm, as they bring questions related to human behaviour that could never be detached from the existing rules and guiding values. New technologies generated by OR present increasing social and environmental impact, mainly in scarce resources' settings (Brans \& Gallo, 2004). The first systematic work intended to treat the ethical implications of OR was written by Wallace (1994), but the theme has only gained notoriety in the 2000 EURO OR opening conference, when an OR code of ethics was proposed: the Oath of Prometeus. The name represents a metaphor for the nature of OR decision making since Prometeus has stolen the fire from the Greek gods to offer it to mankind. If, in the positivist paradigm, the models were built on universal patterns of the natural sciences, as if given by the gods, the introduction of subjectiveness and social impact evaluation could be compared to the theft by the demigod who humanized the fire of knowledge (Brans, 2002).

The first thoughts about OR ethics dealt mostly with the legitimacy of the scientific models, like the existence of objectivity, researcher integrity, data accuracy, and so on. This approach was named "ethics outside OR" by Menestrel \& Wassenhove (2004). The same authors assert that, after the 70's, with the development of multicriteria decision analysis (MCDA) and the introduction of subjectivity in modelling, there appeared an "ethics within OR". Finally, the authors proposed the recognition of an "ethics beyond OR", that considers not only the quantitative method for modelling, but also the qualitative process in which the real world would be apprehended. The success of the latter would depend on communicative reasoning of OR analyst, stakeholders, and all actors affected by the decision, so that a communicational ethics would be a bridge between practical and theoretical dimensions of human behaviour (Habermas, 1992, apud Menestrel \& Wassenhove, 1994).

\section{Specificities of the Scenario of Application: Epidemiology and Health Planning}

Health Services Planning has the health service research epidemiology as one of its most important basic sciences, which provides most of its conceptual and methodological material.

Epidemiology can be defined as "the study of the distribution and determinants of healthrelated states or events in specified populations, and the application of this study to control health problems" (Last, 1995). It has also been questioned about its role as an applied science, experiencing an epistemological crisis in many aspects similar to the one cited above regarding OR.

Susser \& Susser (1996) described the historical evolution of modern epidemiology, with three distinct eras, as follows: 
a) Era of sanitary statistics and miasma theory to explain disease through poisoning by foul emanations from soil, air and water (first half of the $19^{\text {th }}$ century);

b) Era of infectious disease epidemiology and germ theory, as single agents relate one to one to specific diseases (late $19^{\text {th }}$ century through first half of $20^{\text {th }}$ century);

c) Era of chronic disease epidemiology, with multiple causality disease explained by the "black box model", where exposure is related to outcome without necessity for intervening factors or pathogenesis (latter half of $20^{\text {th }}$ century).

In the first era, many drainage, sewage and urban sanitation actions took place, with a positive impact on population health, albeit the ignorance about the causes of diseases. In the second era, with the theory of disease transmission by microorganisms, focus diverged from socioeconomic factors to understand the spreading of disease. Emphasis is given to the interruption of transmission chains, through vaccine developments, immunologic tests, quarantine measures and, ultimately, antibiotics.

The black box paradigm, called positivist, emerged after the second world war, when cardiovascular disease and neoplasm overcame infectious diseases as the main causes of mortality in industrialized countries. Supported by computational and statistical techniques (mainly linear regressions), the studies related development of a chronic disease to a previous exposure to risk factors. This paradigm, also known as "risk model" or "causal inference model", is still hegemonic, as it has many applications to the evidence based medicine practice (also known as clinical epidemiology), but it is likewise criticized as it underestimates the influence of the social context on the health-disease process (Matida \& Camacho, 2004). In the early 70's, an emancipatory or critical movement, known as Social Epidemiology, emerged to study the social determinants of disease, the excluding economic models and their impact upon life conditions. This current was supported by social sciences' methods and was quite disseminated inside Latin America (Breilh, 1991).

Another variant of criticism proposed the rescue of the epidemiology as a discipline that organizes the Public Health, with a systemic and integrative approach. This stream is characterized by what Koopman (1996) calls epidemiology's "transition from a science that identifies risk factors for disease to one that analyzes the systems that generate patterns of disease in populations". Castellanos (1995) affirms that epidemiology has, as its main goal, the description and the explanation of whole communities' health phenomena and their hierarchical interactions, for transformation. Samaja proposes that epidemiology works as open systems, and the interpretation of health events must consider differing levels: the structure one (level of the organization), the contextual level (above, environment), and the analytical level (beneath, purposeful parts). These statements match those of the OR reformist or participative paradigm.

It is noteworthy that the legitimacy of epidemiology as a discipline has been associated with Habermas thoughts in the last decades. That is, the validity of its assumptions has assumed the form of a communicative discourse operating between all points of view of the actors involved in the health-disease process study (Ayres, 1994). According to Almeida Filho (1989), the epidemiologic models are heuristic instruments that represent and communicate ideas, having syntax (set of rules that define the relations inside a model) and semantics (meaning of the model's elements). The positivist models presented by the black box paradigm treats semantics, and have no preoccupation with syntax; syntax and semantics are emphasized by systemic approaches that consider shared subjectiveness. 
With the social component of epidemiology being rescued, the discipline has assumed a protagonist role in health planning by means of diagnosis of health conditions, formulation of plans, organization of health services, definition of resource allocation and assessment of systems, programs, and health policy (Teixeira, 1999). In Brazil, the epidemiologic approach for defining priorities in health planning was established back in the 1988 Republican Constitution, with the creation of the National Unified Health System (SUS).

Health planning assumed by the government emerged in socialist countries as an alternative regulatory mechanism to the market economy. These models have influenced the health planning in Latin America at the 60 's, and were at the beginning normative, technocratic, and based on solely one actor, subordinating the shared subjectiveness to the necessity of economic development (Rivera, 2003). In this case, the main epidemiologic indicators that guided health planning decisions were: magnitude (based on proportional mortality), vulnerability (to treatment by current technologies) and social transcendence of diseases (age impact on population).

Aside from the above positivist model of health planning, there was room for the emergence of the Strategic Health Planning (SHP) in the 70's, assuming the political viability as an important criteria for decision making, and calling for a participative approach in the definition of priorities (Rivera, 1989). In this case, many methodologies deriving from soft OR were incorporated to enhance the communicative flow and enable the players to reach an agreement. Techniques of MCDA also influenced the SHP practices, to construct operational matrices. SHP, thus, begun to incorporate the critical and, to a lesser extend, the reformist paradigm.

Still some criticism was raised against SHP, namely: the planning technique did not consider the cultural viability of the generated proposals and it lacks methods that enhance cooperative negotiation. These latter would be emphasized in the literature of the so called Communicative Action planning (Rivera \& Artmann, 1995). Once more, these theories and methods were based on the rational cognitive theory of Habermas, aiming to generate consensus over the organization's proposals to face and solve the population's health problems in its social and historical dynamics.

\section{Synthesis: Lost and Found in Translation between Operational Research and Health Service Epidemiology in order to enhance Health Planning and Policy}

Management science applications, either public or private, and social planning share concepts and methodologies, historical experiences and paradigmatic (r)evolutions. Figure 1 shows the correspondences amongst OR, epidemiology and health planning as presented in previous sections.

Although epidemiology precedes OR in almost a century, both disciplines have experienced a huge growth after the Second World War, supported by the development of computational tools and assumed a predominant positivist paradigm. At that time, the mathematical algorithms were sufficient to deal with strategic enterprise problems and the statistic causal inference generated important knowledge to the development of preventive and clinical medicine. 

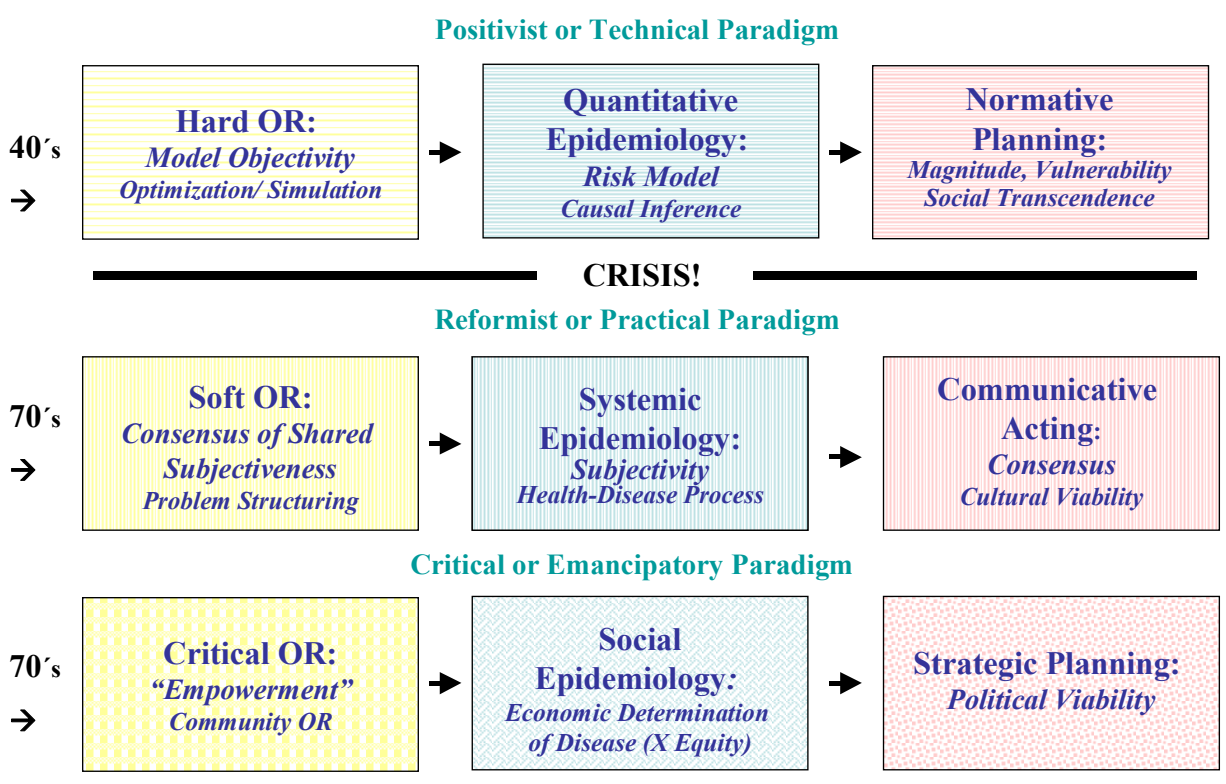

Figure 1 - Paradigmatic correspondences between OR, Epidemiology and Health Planning (according to Habermas' Theory of Knowledge).

In the seventies, both disciplines experienced an epistemological crisis, associated with detachment of their methods from important social problems. From then on, based on social science methodologies, systemic approaches and political inclusion for empowerment criteria were incorporated by the disciplines, shaping the reformist and the critical paradigm, respectively. Note that each paradigm assumes one different component of Habermas theory of knowledge.

But there is still room for joining together these areas. In common sense, and even in specialized literature, the terms administration, planning and management appear as interchangeable. Nevertheless, operational research usually is instructed by departments of administration or engineering, and health planning and epidemiology disciplines are usually confined to public health or health administration schools. Until now, there is no systematic dialogue between these two scientific areas. For a typical epidemiologist, operational research means field epidemiologic research; yet, many OR analysts consider that epidemiology just consists in the study of epidemics processes.

Fortunately, there are exceptions in the conceptual, practical and methodological fields. In the conceptual field, Avedis Donabedian (1980) developed a theoretical model to guarantee quality assurance in health care, which has been a reference for health services epidemiology and administration. According to him, there are three approaches to assess quality of care:

a) Structure: or conditions under which care is provided, as material resources, human resources, organizational characteristics;

b) Process: activities that constitute health care, as prevention, diagnosis, treatment, rehabilitation, patient education, usually carried out by professional personnel; 
c) Outcome: mean changes in individuals or populations, desirable or undesirable, which can be attributed to health care, as death, patient satisfaction, and so on.

Inferences about quality are not possible unless there is a predetermined relationship among the three approaches, that is, structure is a condition for a good process, which is a determinant factor to a desirable outcome.

In the practical or operational field, the early OR British reformers applied their techniques to local governments and the National Health Service (NHS). Concerning the NHS OR applications in the 70's, Smith (1995) argues that the traditional OR approach fails not because its model is an inadequate representation of reality, but because it does not acknowledge the priorities of the manager or politician in charge of the implementation. In other words, the model was mainly positivist oriented, and could be enhanced through the incorporation of new systemic and critical approaches.

In the methodological field, after the seventieth, both fields proposed a reformist perspective and placed particular emphasis on action-research for negotiation and management of change. To deal with that paradigm shift, OR analysts and health managers had a change in posture, from an advisor of top management, to a mediator of all actors trying to reach consensus (Vidal, 2006); from then on, abandoning the prescriptive and detached attitude, and thus, modifying and being modified by the modelling and planning process.

Nowadays, health services research is considered a multidisciplinary field of inquiry, both basic and applied, that examines the use, costs, quality, accessibility, delivery, organization, financing and outcomes of health care services. Research thus aims to increase knowledge and understanding of the structure, processes and effects of health services to individuals and populations (Aday et al., 2004). To deal with the complexity of the theme, Fulop et al. (2001), after a workshop that joined different disciplines that usually deal with the organization and delivery of health services, published a book presenting their ongoing paradigms, uses and limitations(including epidemiology and OR). It is important to note that, in the chapter dedicated to OR, Rosenhead affirms that the major current limitation on the use of OR is its relatively weak institutionalization as a discipline within operational levels of health services.

Finally, concerning the link between health service research and health policy, we consider that the first produces knowledge about the performance of the healthcare system, and policy analysis applies this knowledge in defining problems and evaluating policy alternatives. What must be kept in mind is that, between the health research results and the policy decision making, there is a moment of judgement by the health manager. The degree to which the results of an evaluation are taken into consideration by decision-makers varies according to their credibility, theoretical foundation and pertinence (Contandriopoulos, 2006). Policy-making processes and scientific practices themselves often appear to pose obstacles to the actual utilization of research results. Many such obstacles result from reifying views of the decision-making process and objectivist conceptions of science. Souza \& Contandriopoulos (2004) affirm that the use of research results should thus become an exchange of significant metaphors between policy-makers and scientists. According to the authors, adoption of pluralistic research systems and intensification of interfaces between researchers and policy-makers in a context of knowledge-sharing would be the main strategies to improve this exchange. Such strategies would be efficient to the extent that they succeeded in drawing science and common sense closer together, thereby transforming both.

Pesquisa Operacional, v.30, n.2, p.371-386, Maio a Agosto de 2010 


\section{Brief Look at the Literature Review on Health Efficiency Studies: OR Analyst and Health Manager's Perspectives}

There is an absolute consensus that health care services research and planning are complex societal problems (CSP) and that OR can provide useful tools and methodologies to deal with them. CSP and healthcare issues are multi dimensional and interdisciplinary, difficult to formulate, usually have lack of data, demand multiple distinct methodologies, have great impact on society, and comprise power and emotion of the different actors involved in the problem handling process (DeTombe, 1996, 2002).

Additionally, along with an ever expanding incorporation of new technologies, healthcare services consume increasing proportions of GDP (Gross Domestic Product), that are not necessarily associated with a better quality of care (Retzlaff-Roberts et al., 2004). Also, the market has a low power of regulation for the healthcare sector. For these reasons, OR efficiency and performance studies have been frequently chosen to handle the problem.

Regarding the efficiency studies, we can use a couple of examples to compare the different perspectives of the OR analyst and the health manager, in order to look for a better understanding and interaction between these two actors.

The most comprehensive OR literature review on health efficiency studies were published by Hollingsworth (2003) and O'Neill et al. (2007). The latter emphasized the use of Data Envelopment Analysis (DEA) to assess hospital efficiency and standardize the taxonomy for a better understanding and comparison of the studies. The former showed 188 health efficiency papers, published in OR or Economics journals, and presented a descriptive statistics of the methodologies used (50\% used DEA, and 12\%, Stochastic Frontier Analysis), units of analysis (mainly hospitals $-50 \%$ ), variables and chosen models and/or orientations, mean values obtained, presenting a detailed picture of the adopted techniques.

Although a very important perspective, it is not exactly what the health manager expects from a literature review on health efficiency studies. The health manager or health professional wants to know the state of art of the knowledge acquired from the method, the circumstances where the technique applies well, and the scope of the hypothesis to be tested.

As a bricolage exercise, we searched in Medline (a worldwide used database on health and medical scientific publications) the papers with the keyword: Data Envelopment Analysis, and had the following results: there have been published 141 papers in health journals since the first publication in 1983 (Nunamaker), 62\% of them had hospitals or primary care centres as units of analysis, and almost all of them used classical models, barely incorporating the more recent developments of the method, as the weight restrictions, that could enrich the reliability of the technique (as they assume the reformist paradigm by inserting the specialist opinion; Allen et al., 1997).

On the other hand, it is clear that the use of DEA in health literature is spreading throughout the world. $70 \%$ of the papers were published after the year 2000 , and there are publications in the current century - from all earth continents. In Africa, for example, there is an evident effort made by WHO (World Health Organization) to use DEA as an aiding tool to organize the health system (Kirigia et al., 2002).

Concerning the main uses and scenarios for application, they are: a) Practical use to aid decision making (75 papers): by constructing the best practice frontier, and defining the benchmarks, the manager decides which resources to reduce or which products to increase, 
depending if the model is input or output oriented; b) Studies used to organize healthcare systems (38 papers), as the African experience cited above, and others to assess impact of hospital financing reforms (Sommersgutter-Reichman, 2000) or new regulatory strategies (Biørn et al., 2003); c) Association Studies (25 papers): frequently using linear regression, to evaluate variables associated with better or worse efficiency score, like teaching and research activities (Schreyögg \& Von Reitzenstein, 2008), or socio-demographic variables, d) Clinical studies (only 3): to develop a response to treatment model (Friesner et al., 2005) or to establish a neurotrauma prognosis index (Nathanson et al., 2003).

This kind of information appears more suitable to the health manager, in order to track his interest. Concerning some management related results that could be used in his routine work, we have some published experiences, like: a) In Norway, hospital merging are associated with increased efficiency only when the complex adopted a centralized management (Kjekshuh \& Hagen, 2007); b) In USA, lack of efficiency has not been associated with closure decisions (Lynch \& Ozcan, 1994); c) In Greece, regionalisation of the system has advantages, but not efficiency related (Aletras et al., 2007), d) Incentive programs to health professionals based on production have been worldwide associated with increasing efficiency, with low cost of regulation (Felder \& Schmitt, 2004). Even if we consider that the efficiency measure of DEA is always relative to the specific group of units being analysed, these examples could, for instance, represent important case studies, that is, a kind of tool that the manager already values and is used to deal with in his day by day practice.

Perhaps, this sole example shows the importance of also exploring a field of metaphors in order to enhance a dialogical interdisciplinary approach. Optimization, maximization, simulation, benchmarks are current terms used in the discourse of health care managers, even if they are not associated to any quantitative modelling at all. We could observe the same for the efficiency issues, one of the main quality dimensions cited by Donabedian (1980), which permeates the idea of transforming resources into products using an accountable way, not only financial, but also according to the epidemiological demands of society. In this sense, Data Envelopment Analysis has reached a good acceptance by health care researchers and managers, mainly as a tool that compares multi-inputs and multi-outputs units, that points to possible forms of amelioration and does not depend on a known statistical previous distribution.

Simultaneously, even inside the OR academic society, a single methodology like DEA can be explored according to different paradigms. The technique was created as a linear programming model in the core of the positivist paradigm, incorporated subjectivity when there was need to insert weight restrictions in order to enhance reliability (reformist paradigm) and had also been used to empower the stakeholders when they began to participate in the modelling process, by choosing models, variables and orientations in participative workshops (emancipatory paradigm). As already cited above, the DEA publications in Public Health and Epidemiologic journals use mainly the classic models and are still dominated by the positivist paradigm. As the metaphoric and dialogical interdisciplinary practice become more systematic, it will certainly be strengthened by the incorporation of the other complementary paradigms, toward the development of a new postnormal science. Like in most complex societal problem, facts are uncertain, values in dispute, stakes high and decisions urgent, and there is a room for an extended peer community consisting of all those affected by an issue who are prepared to enter into dialogue on it. According to Funtowicz \& Ravetz (1993), this extension is necessary for assuring the quality of the process and of the product. 


\section{Conclusions}

Much is yet to be said about the interdisciplinary debate between OR and Health Services Planning \& Epidemiology. The present paper tried to show, from an epistemological dimension, how these disciplines do speak the same language, although they still do not exercise the dialog in its plenitude. They experienced similar historical turmoil and search that evolved to comparable internal solutions. The question to be answered is how to approximate their own interests, points of view and priorities in such a way that the results of one's enquiry could be immediately absorbed by the other without necessity of an expert mediation. This is a key factor to guarantee the application of the scientific findings.

We hope that some of the reflections above can introduce insights to construct an agenda that brings together the distinct scientific areas. Some are to be mentioned beneath:

- The multidisciplinary approach to CSP must be treated not only in the plan of actors and specialists, but also in the plan of epistemological cognitive factors. The real world is everywhere.

- The multimethodology to be adopted to deal with complex social problems may consider the coexistence of different paradigms. Even if you look to a simple technique, such as Data Envelopment Analysis, created in the core of the positivist approach, the inclusion of weight restrictions, and research-action methodologies to create consensus about the units, variables and interpretations, assumes the reformist and critical paradigm, intensifying reliability.

- As there are many actors involved, and many points of view, it is interesting that the scientific agenda is to be attached to an ethical one.

- Efforts should be made to create OR nucleus or departments inside health care settings.

- Besides the techniques to structure the problems, one would need to investigate techniques to guarantee that the results of health services research will really be put in practice by health policy decision makers. This was exemplified with the case of the significant metaphors. In the case of DEA results, for example, the transformation of the published results in case studies could help to understand, to apply and validate the method.

- Any researcher involved in the investigation must also have a commitment with the actual application of the findings.

- Concerning the academic field development, it is noteworthy to introduce the OR technical novelties in the health application scenario, extending from the classic models already used. Also, the scientific language should be understandable to all actors that handle the problem to be analyzed. That is, to facilitate an interdisciplinary dialogue and guarantee an actual problem solving process, science should be not only intelligent, but also intelligible.

Finally, although a systematic review of the literature was not done in this paper, the exercise made with a single technique of OR (DEA) to deal with an unique dimension of healthcare quality (efficiency) was able to show how important and useful the OR methodologies can be to enrich the Health Services Planning \& Epidemiologic knowledge. 


\section{References}

(1) Ackoff, R.L. (1979a). The Future of Operational Research Is Past. J. Oper. Res. Soc., 30, 93-103.

(2) Ackoff, R.L. (1979b). Resurrecting the Future of Operational Research. J. Oper. Res. Soc., 30, 207-218.

(3) Ackoff, R.L. (1999). Ackoff's Best: His Classic Writings on Management. John Wiley \& Sons, Inc., New York.

(4) Ackoff, R.L. (1981). Creating the Corporative Future. Wiley, New York.

(5) Aday, L.A.; Begley, C.E.; Lairson, D.R. \& Balkrishnan, R. (2004). Evaluating the Healthcare System: Effectiveness, Efficiency and Equity. $3^{\text {rd }}$ ed., Health Administration Press, Washington, DC.

(6) Aletras, V.; Kontodimopoulos, N.; Zagouldoudis, A. \& Niakas, D. (2007). The ShortTerm Effect on Technical and Scale Efficiency of Establishing Regional Health Systems and General Management in Greek NHS Hospitals. Health Policy, 83(2-3), 236-245.

(7) Allen, R.; Athanassopoulos, A.; Dyson, R.J. \& Thanassoulis, E. (1997). Weights Restrictions and Value Judgments in Data Envelopment Analysis: Evolution, Development and Future Directions. Annals of Operations Research, 73, 13-34.

(8) Almeida Filho, N. (1989). Epidemiologia Sem Números: Uma Introdução Crítica à Ciência Epidemiológica. Ed. Campus, Rio de Janeiro.

(9) Ayres, J.R.C.M. (1994). Interpretação Histórica e Transformação Científica: A Tarefa Hermenêutica de Uma Teoria Crítica da Epidemiologia. Rev. Saúde Pública, 28(4), 311-319.

(10) Biørn, E.; Hagen, T.P.; Iversen, T. \& Magnossen, J. (2003). The Effect of ActivityBased Financing on Hospital Efficiency: A Panel Data Analysis of DEA Efficiency Scores 1992-2000. Health Care Management Science, 6(4), 271-283.

(11) Brans, J.P. (2002). OR, Ethics and Decisions: the OATH of PROMETHEUS. Eur. J. Oper. Res., 140, 191-196.

(12) Brans, J.P. \& Gallo, G. (2004). Ethics in OR/MS: Past, Present and Future. 4 OR Quarterly Journal of the Belgium, French and Italian Operational Research Societies, 2, 95-110.

(13) Breilh, J. (1991). Epidemiologia: Economia, Política e Saúde. Trad. Luis Roberto de Oliveira, UNESP/ HUCITEC, São Paulo.

(14) Castellanos, P.L. (1995). Lo Ecológico en Epidemiologia Aplicada en Salud Pública. III Congresso Brasileiro de Epidemiologia. Salvador, Mimeo, $11 \mathrm{p}$.

(15) Checkland, P \& Scholes, J. (1990). Soft Systems Methodology in Action. John Wiley \& Sons Ltd., Chichester.

(16) Contandriopoulos, A.-P. (2006). Avaliando a Institucionalização da Avaliação. Ciência \& Saúde Coletiva, 11(3), 705-711. 
(17) Detombe, D.J. \& Hart, H.’t. (1996). Using System Dynamic Modeling Techniques for Constructing Scenarios of Societal Problems. In: Analyzing Societal Problems [edited by Dorien J. Detombe and Cor Van Dijkum]. Hampp Verlag, Munchen.

(18) Detombe, D.J. (2002). Complex Societal Problems in Operational Research. Eur. J. Oper. Res., 140, 232-240.

(19) Donabedian, A. (1980). Explorations in Quality Assessment and Monitoring. Vol. I. In: The Definition of Quality and Approaches to its Assessment. Michigan, Health Administration Press, Ann Harbor.

(20) Felder, S. \& Schmitt, H. (2004). Data Envelopment Analysis Based Bonus Payments. Theory and Application to Inpatient Care in the German State of Saxony-Anhalt. Eur. J. Health Econ., 5(4), 357-363.

(21) Friesner, D.; Neufelder, D.; Raisor, J. \& Khayum, M. (2005). Benchmarking Patient Improvement in Physical Therapy with Data Envelopment Analysis. Int J Health Care Qual Assur, 18(6-7), 441-457.

(22) Fulop, N.; Allen, P.; Clarke, A. \& Black, N. (2001). Studying the Organization and Delivery of Health Services. Routledge, London.

(23) Funtowics \& Ravetz (1993). Science for the Post-Normal Age. Futures, 25/7 September, 739-755.

(24) Gass, S.I. \& Assad, A.A. (2005). An Annotated Timeline of Operations Research An Informal History. Kluwer Academic Publishers.

(25) Habermas, J. (1998). The Inclusion of the Other. Studies in Political Theory. MIT Press, 1992. Moral Consciousness and Communicative Action (studies in contemporary German social thought). MIT Press, Boston, MA.

(26) Hollingsworth, B. (2003). Non-Parametric and Parametric Applications Measuring Efficiency in Health Care. Health Care Management Science, 6, 203-218.

(27) Kirby, M.W. (2007). Paradigm Change in Operations Research: Thirty Years of Debate. Operations Research, 55(1), 1-13.

(28) Kirigia, J.M.; Emrouznejad, A.; Sambo, L.G.; Munguti, N. \& Liambila, W. (2002). Measurement of Technical Efficiency of Public Hospitals in Kenya: Using Data Envelopment Analysis. J Med Syst, 26(1), 39-45.

(29) Kjekshuh, L. \& Hagen, T. (2007). Do Hospital Mergers Increase Hospital Efficiency? Evidence from a National Health Service Country. J. Health Serv Res Policy, 12(4), 230-235.

(30) Koopman, J.S. (1996). Emerging Objectives and Methods in Epidemiology. Am J Public Health, 86, 630-2.

(31) Last, J.M. (1995). A Dictionary of Epidemiology. $3^{\text {rd }}$ Edition, Oxford University Press, USA.

(32) Lynch, J.R. \& Ozcan, Y.A. (1994). Hospital Closure: An Efficiency Analysis. Hosp Health Serv Adm, 39(2), 205-220.

(33) Matida, A.H. \& Camacho, L.A.B. (2004). Pesquisa Avaliativa e Epidemiologia: Movimentos e Síntese no Processo de Avaliação de Programas de Saúde. Cad. Saúde Pública, 20(1), 37-47. 
(34) Menestrel, M. Le \& Wassenhove, L.N. Van (2004). Ethics Outside, Within, or Beyond OR Models? Eur. J. Oper. Res., 153, 477-484.

(35) Morgan, G. (1986). Imagens da Organização. Tradução: Cecília Whitaker Bergamini \& Roberto Coda, Atlas, São Paulo.

(36) Nathanson, B.H.; Higgins, T.L.; Giglio, R.J.; Munshi, I.A. \& Steingrub, J.S. (2003). An Exploratory Study Using Data Envelopment Analysis to Assess Neurotrauma Patients in the Intensive Care Unit. Health Care Management Science, 6(1), 43-55.

(37) Nunamaker, T.R. (1983). Measuring Routine Nursing Service Efficiency: A Comparison of Cost per Patient Day and Data Envelopment Analysis Models. Health Serv Res., 18, 183-208.

(38) O’neill, L.; Rauner, M.; Heidenberger, K. \& Kraus, M. (2007). A Cross-National Comparison and Taxonomy of DEA-Based Hospital Efficiency Studies. SocioEconomic Planning Sciences, 42, 158-189.

(39) Rivera, F.J.U. (2003). Análise Estratégica em Saúde e Gestão pela Escuta. Editora FIOCRUZ, Rio de Janeiro.

(40) Retzlaff-Roberts, D.; Chang, C. \& Rubin, R.M. (2004). Technical Efficiency in the Use of Health Care Resources: A Comparison of OECD Countries. Health Policy, 69, 55-72.

(41) Rivera, F.J.U. (1989). Agir Comunicativo e Planejamento Social (Uma Crítica ao Enfoque Estratégico). Editora FIOCRUZ, Rio de Janeiro.

(42) Rivera, F.J.U. \& Artmann, E. (1995). Planejamento e Gestão em Saúde: Flexibilidade Metodológica e Agir Comunicativo. Ciência \& Saúde Coletiva, 4(2), 355-365.

(43) Rosenhead, J. (2001). Operational Research. In: Studying the Organization and Delivery of Health Services [edited by N. Fulop, P. Allen, A. Clarke and N. Black], Routledge, London.

(44) Rosenhead, J. (Ed.) (1989). Rational Analysis for a Problematic World: Problem Structuring Methods for Complexity, Uncertainty, and Conflict. Wiley \& Sons.

(45) Samaja, J. (1993). Epistemologia e Metodologia: Elementos para Una Teoria de la Investigación Cientifia. Eudeba, Buenos Aires.

(46) Schreyögg, J. \& Von Reitzenstein, C. (2008). Strategic Groups and Performance Differences Among Academic Medical Centers. Health Care Management Review, 33(3), 225-233.

(47) Smith, P. (1995). Large Scale Models and Large Scale Thinking: The Case of the Health Services. Omega, Int. Mgmt. Sci., 23(2), 145-157.

(48) Sommersguter-Reichmann, M. (2000). The Impact of the Austrian Hospital Financing Reform on Hospital Productivity: Empirical Evidence on Efficiency and Technology Changes Using a Non-Parametric Input-Based Malmquist Approach. Health Care Management Science, 3, 309-321.

(49) Souza, L.E.P.F. \& Contandriopoulos, A-P. (2004). O Uso de Pesquisas na Formulação de Políticas de Saúde: Obstáculos e Estratégias. Cad. Saúde Pública, 20(2), 546-554. 
(50) Susser, M. \& Susser, E. (1996). Choosing a Future for Epidemiology: I. Eras and Paradigms. Am. J. Public Health, 86(5), 668-673.

(51) Teixeira, C.F. (1999). Epidemiologia e Planejamento de Saúde. Ciência e Saúde Coletiva, 4(2), 287-303.

(52) Ulrich, W. (1994). Critical Heuristics of Social Planning: A New Approach to Practical Philosophy. Wiley, Chichester.

(53) Vidal, R.V.V. (2006). Operational Research: A Multidisciplinary Field. Pesquisa Operacional, 26(1), 69-90.

(54) Wallace, W.A. (1994). Ethics in Modeling. Pergamon, New York. 